\title{
DOIS SELOS DE ÂNFORAS DRESSEL 20 PROVENIENTES DA VILLA ROMANA DE PIDDINGTON - NORTHAMPTON, REINO UNIDO*
}

Pedro Paulo Abreu Funari ${ }^{1}$

O senhor Roy Friendship enviou ao autor um molde do selo n $\mathrm{n}^{\circ} \mathrm{2}$ (abaixo) e a alça anfórica que carrega o selo n01 (também abaixo):

1. III ENNI IVL (Palma). Selo não publicado (cf. CIL XV, 2, 2819,f; CALLENDER 581; REMESAL 86; PONSICH 2,43,74) encontrado na Villa Romana de Piddington (BB-CC 23-25 L6 HH Pid. H/F 90); medindo 2.11 x 0.6 polegadas romanas. Produzido em Huertas de Nicasio, e datado em Roma (160 d.C) e Augst (70-120 d.C). Em sua inscrição lê-se: III <trium> ENNI(orum) IVL(iorum).

2. SP AE. Selo não publicado (cf. HISPSAENI, CIL XV, 2, 2914; CALLENDER 1550h; PONSICH 2,43,79; REMESAL 131) encontrado no mesmo sítio (X/20 F567, depósito 2, L\&, sala 39, Pid. H/F 91); medindo $1.10 \times 0.6$ polegadas romanas. Produzido na mesma olaria e datado em Avenches (50-100 d.C). Em sua inscrição lê-se: <HI $>S P($ ani) $<S>A E(n i)$, ou saenianensis figlinae.
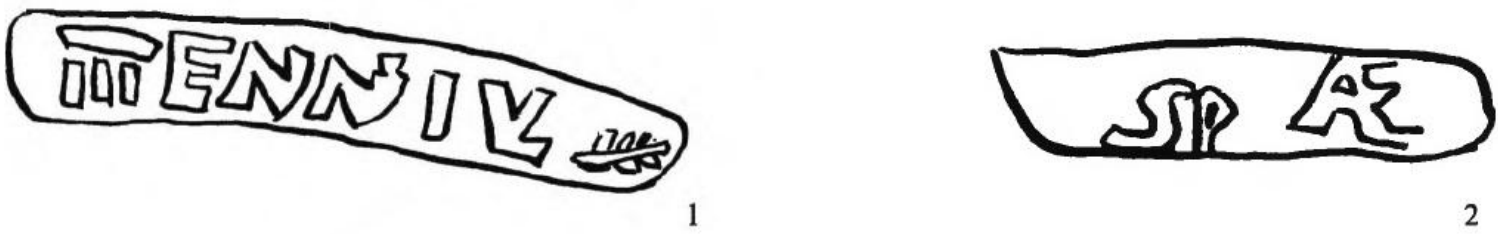

Ambos os selos são provenientes da mesma olaria, Huertas del Río, situada à margem direita do rio Bétis, ou Vale Guadalquivir, em um sítio

\footnotetext{
* Artigo originalmente publicado como FUNARI, P.P.A. Two Dressel 20 Stamps From Piddington Villa, Northampton, U.K. Revista do Museu de Arqueologia e Etnologia. São Paulo, MAE/USP, 4: 227, 1994. Tradução: Filipe Noé Silva - Doutorando IFCH/Unicamp.

1 Professor Titular, Universidade Estadual de Campinas, Unicamp. E-mail: ppfunari@uol.com.br
} 
arqueológico ligado a Axati, antiga cidade romana (atual Lora del Río) do Conuentus Hispalensis. A olaria era conhecida como saenianenses figlinae desde os anos 60 d.C. Caius Ennius Hispanus, bem como Hispanus Saen( ) também são datados do primeiro século d.C. Os três Enii Iulii, que também utilizaram a mesma olaria, são datados do período Antonino, e pode-se mesmo supor que os Enii estão relacionados a Caius Ennius Hispanus (século I d.C). Genaro Chic associa o nome da olaria a um riacho, Riuus Saenus. Os selos III Eniorum Iuliorum foram descobertos na Inglaterra, em Londres, Corbridge, Holt, Brecon, York, Brecongaer, Richborough, Shorden Brae, Silchester, StokeAss, Wroxeter e Chester. Já os inscritos Hisp( ) Sae( ) encontrados em Londres, Caersws, York e Cirencester.

\section{Referências}

CALLENDER, M. Roman amphorae, with an index of stamps. Oxford: Oxford University Press, 1965.

PONSICH, M. Implantation rurale antique sur le Bas-Guadalquivir II. Paris: De Boccard, 1979.

REMESAL, J. La annona militaris y la exportación del aceite bético a Germania. Madrid: Universidad Complutense, 1986. 